\title{
A Compact Lowpass Filter with Ultra Wide Stopband using Stepped Impedance Resonator
}

\author{
Mohsen HAYATI, Farzin SHAMA \\ Dept. of Electrical Engineering, Kermanshah Branch, Islamic Azad University, Kermanshah, Iran \\ mohsen_hayati@yahoo.com,f.shama@aut.ac.ir \\ Submitted August 7, 2016 / Accepted November 22, 2016
}

\begin{abstract}
In this paper, a compact asymmetric-shaped microstrip lowpass filter (LPF) using a stepped impedance resonator is presented. An ultra wide stopband with high attenuation in the stopband region, within very small circuit area is achieved for the proposed filter using novel asymmetric structures for resonator and suppressor. The transmission zeros of the resonators can be adjusted as a function of high impedance and low impedance microstrip lines, and due to the asymmetric structure, the proposed suppressing cell can be located within the resonator structure without occupying a large area. For verification, a $2.92 \mathrm{GHz} \mathrm{LPF}$ is designed and fabricated. The experimental results, in comparison with the other LPFs, show that the proposed LPF has significant advantages in the stopband characteristics with acceptable sharp roll off. The measured passband insertion loss is below $0.1 \mathrm{~dB}$, and the rejection band over $-20 \mathrm{~dB}$ is obtained from $3.42 \mathrm{GHz}$ to $36.2 \mathrm{GHz}$. The size of filter corresponds to compact electrical size of $0.156 \lambda_{g} \times 0.128 \lambda_{g}$, where $\lambda_{g}$ is the guided wavelength at $2.92 \mathrm{GHz}$. Also, the maximum variation of the group delay in 80 percent of the passband region is only about $0.2 \mathrm{~ns}$.
\end{abstract}

\section{Keywords}

Lowpass filter, microstrip, stepped impedance resonator, ultra wide stopband

\section{Introduction}

Microstrip lowpass filters (LPFs) are highly demanded in modern communication systems to suppress harmonics and spurious signals [1]. To increase the order of filter, more sections are needed, but increasing the sections will also raise the loss in the passband [2], [3]. With respect to these facts and to improve the performance of LPFs, various methods have been presented in [3-17]. A wide stopband lowpass filter using U-shaped resonators has been fabricated in [3], which has a gradual transition band response. A LPF using microstrip stepped-impedance hairpin resonator has been presented in [7], which has a sharp response in the transition band, but the return loss in the stopband is not high and the stopband width is not wide enough. Another LPF using a microstrip line section and an interdigital capacitor has been presented in [8], although the frequency response in the passband is appropriate, but the stopband width is not satisfactory. A lowpass filter with an embedded bandstop structure has been designed in [9]. However, the circuit size is small but the stopband is not wide enough. In [10], a microstrip LPF with sharp roll off and an approximately wide stopband has been presented. Nevertheless, the overall size is large. Design of a lowpass filter using a slit-loaded tapered compact microstrip resonator cell (SLTCMRC) has been presented in [11] with a very sharp rejection band, but it suffers from large size. A compact and broad stopband LPF using a stepped impedance resonator (SIR) has been presented in [12], but it has gradual transition band and poor return loss in the stopband. A LPF with a novel application of shunt open stubs at the feed points of a center fed coupled line hairpin resonator with very wide stopband and sharp response has been proposed in [13], but the attenuation level in the stopband is not satisfactory. In [14-16], the presented LPFs have wide stopband with considering to attenuation level of $-15 \mathrm{~dB}$ or $-17 \mathrm{~dB}$. However, with regarding to attenuation level of $-20 \mathrm{~dB}$, the stopband regions of these filters are not wide enough. A novel LPF with wide stopband and sharp roll-off using a tapered resonator has been fabricated in [17], which has a large circuit size.

In this paper, an asymmetric-shaped lowpass filter using stepped impedance resonator with a simple structure is implemented. The proposed LPF achieves an ultra wide stopband with high attenuation in the stopband and small circuit area. The LPF is designed as follows: At the first step, with the realization of a 3 order elliptic function resonator, a microstrip resonator layout with one adjustable transmission zero is created. With adjusting the transmission zero, the cut-off frequency and roll-off is changed to the desirable value. At the next step, another similar resonator is added symmetrically to add a new transmission zero nearby the previous one, which can guarantee a stopband with a sharper transition band. At the third step, the previous symmetrical structure is reformed to an asymmetric resonator. This trend provides two advantages for designers. The first advantage is size reduction, and the second one is the better insertion loss in the passband due to the increment of the coupling effects between the two reso- 
nators, which can make a better matching. At the last step, to have a wider stopband width, an asymmetric stepped impedance suppressing cell is located in the proposed asymmetric resonator. The asymmetric structures help to occupy a smaller area in comparison with a symmetric topology. So, a compact LPF with ultra wide stopband is designed using a combination of the asymmetric resonator and suppressing cell.

\section{Filter Design}

In the first step, an appropriate prototype L-C lowpass resonator is selected as shown in Fig. 1(a). A three order elliptic function lowpass filter is considered with cut-off frequency $\left(f_{\mathrm{c}}=3.6 \mathrm{GHz}\right)$, source and load impedance $Z_{0}=50 \Omega$. The $\mathrm{S} 12$ frequency response of the resonator is shown in Fig. 1(b). According to the frequency response, it has a sharp roll-off, but the insertion loss has a significant value. The next step is to find an appropriate microstrip realization. Figure 2 shows the proposed microstrip layout for this equivalent circuit. The high impedance lines are used as the inductors and low impedance lines are used as the capacitors. It is clear that the coupling effects are ignored. For high impedance $Z_{\mathrm{H}}$, length of inductance can be obtained from [18]:

$$
d^{\prime}=\left(\lambda_{\mathrm{H}} / 2 \pi\right) \sin ^{-1}\left(\frac{\omega d}{Z_{\mathrm{H}}}\right) \text {. }
$$

Parasitic capacitance associated with inductance can be written as:

$$
C_{\mathrm{d}}=\left(1 / \omega Z_{\mathrm{H}}\right) \tan \left(\frac{\pi d^{\prime}}{\lambda_{\mathrm{H}}}\right) .
$$

For low impedance line $Z_{\mathrm{L}}$, length of capacitance can be acquired from:

$$
d_{1}=(\lambda d / 2 \pi) \sin ^{-1}\left(\omega C Z_{\mathrm{L}}\right) .
$$

Parasitic inductance associated with the capacitance can be written as:

$$
L_{\mathrm{c}}=\left(Z_{\mathrm{L}} / \omega\right) \tan \left(\frac{\pi d_{1}}{\lambda_{\mathrm{L}}}\right)
$$

where $Z_{\mathrm{H}}$ is the high impedance value, $Z_{\mathrm{L}}$ is the low impedance value, $\omega$ is the angular frequency and $\lambda$ is the wavelength of high and low characteristic impedance. To obtain a wider rejection band with better attenuation level and sharper transition band, several ideas are performed step by step in this paper: The primal microstrip realized resonator is simulated as functions of its dimensions. It can be useful to find the most important parameters for optimizing the location of transmission zero to have a required cut-off frequency and sharp roll-off. To obtain a wider rejection band with better attenuation level and sharper transition band, another transmission zero are added nearby the first one, by cascading another similar resonator. Then, the di-

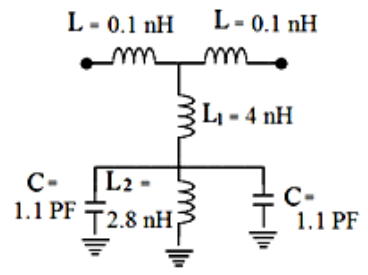

(a)

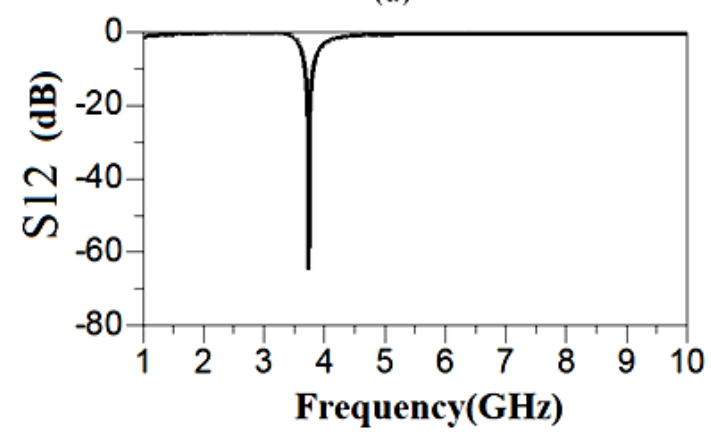

(b)

Fig. 1. (a) The L-C ladder type circuit of the elliptic function resonator. (b) The S12 frequency response of the elliptic function resonator.

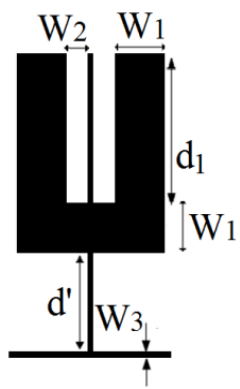

Fig. 2. The microstrip layout for proposed LC resonator.

mensions of the proposed resonator are optimized with an EM simulator (ADS). To obtain a more compact resonator; the stepped impedance lines are bent. With bending the symmetric resonator, an asymmetric-shaped modified resonator can be created. Therefore, the return loss of the primal resonator in the passband is improved. This improvement causes lower insertion loss in the passband. To extend the stopband width, three discontinuities as steps in width are added to the high impedance feeding lines asymmetrically, which operate as a suppressing cell. This results in the creation of transmission zeroes at the undesired high frequencies, which suppress the level of harmonics. Finally, by tuning and optimizing the proposed LPF with an EM simulator (ADS), the widest stopband region is achieved. The simulated $\mathrm{S}_{12}$ parameter of the proposed resonator as a function of the gap distance between the open-end stubs $\left(W_{2}\right)$ is shown in Fig. 3(a). As seen, by changing the gap, the transmission zero does not move significantly, thus the coupling capacitance can be ignored. As seen from Fig. 3(b), by increasing $W_{1}$ from $0.5 \mathrm{~mm}$ to $1.2 \mathrm{~mm}$, the capacitance of $\mathrm{C}$ becomes larger and the transmission zero moves to the lower frequencies to create a sharper transition band. Also, we can achieve a sharper transition band by increasing the inductance of $L_{1}$ that is done by increasing the length of $d^{\prime}$ from $1.5 \mathrm{~mm}$ to $2.5 \mathrm{~mm}$, 


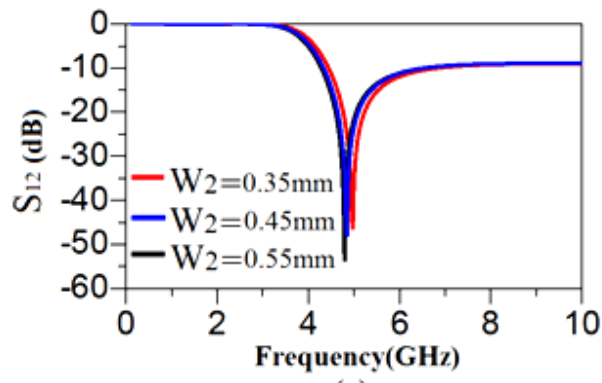

(a)

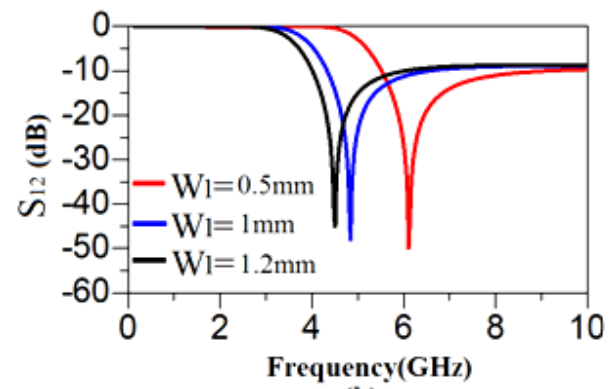

(b)

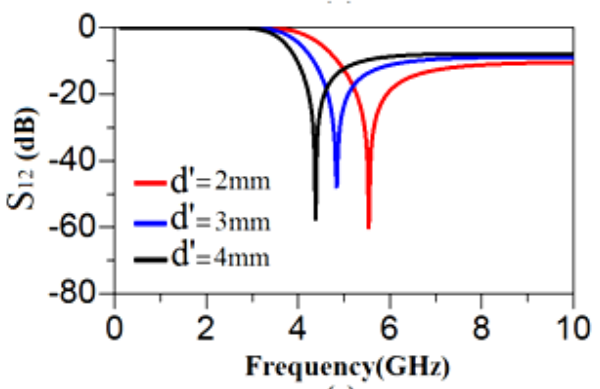

(c)

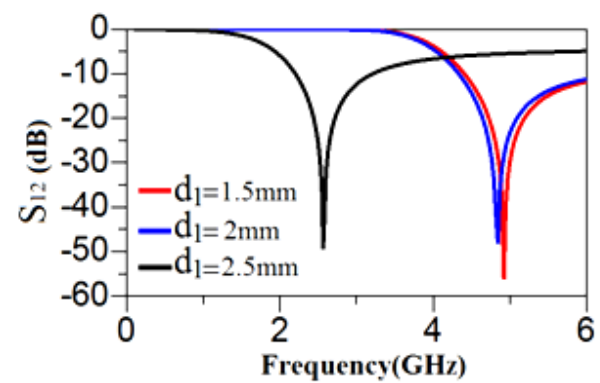

(d)

Fig. 3. (a) The simulated S12-parameter of the proposed resonator as a function of $W_{2}$. (b) The simulated S12-parameter of the proposed resonator as a function of $W_{1}$. (c) The simulated S12-parameter of the proposed resonator as a function of $d^{\prime}$. (d) The simulated S12-parameter of the proposed resonator as a function of $d_{1}$.

as shown in Fig. 3(c). The inductance of $L_{2}$ has a significant effect on the transmission zero, as shown in Fig. 3(d). By increasing the length of $d_{1}$ from $2 \mathrm{~mm}$ to $4 \mathrm{~mm}$, the inductance of $L_{2}$ becomes larger and the transmission zero moves to the lower frequencies, rapidly.

With above discussions, the dimensions of the resonator are optimized to have a required cut-off frequency and sharp roll-off. The resonator creates a transmission zero at $4.84 \mathrm{GHz}$ with the attenuation level of $-48 \mathrm{~dB}$, which can provide the $-3 \mathrm{~dB}$ cut-off frequency nearby 3.6 GHz. But, to obtain a wider rejection band with better attenuation level and sharper transition band, other trans-

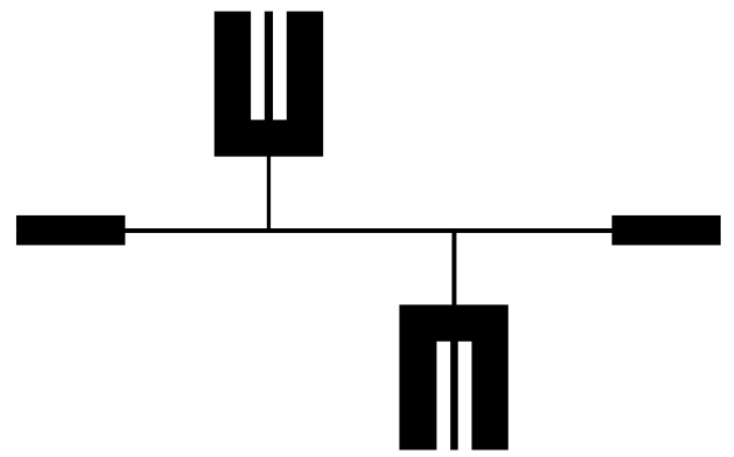

Fig. 4. The proposed resonator.

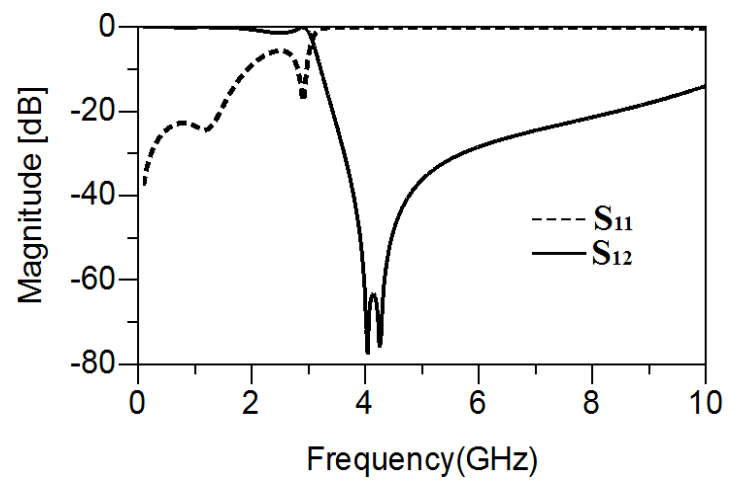

Fig. 5. The simulated S-parameters of the proposed resonator.

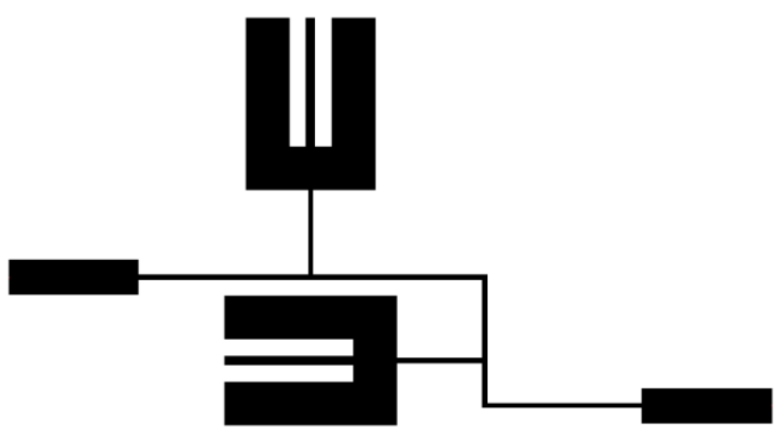

Fig. 6. The proposed modified resonator.

mission zeros are added nearby the first one, by cascading another similar resonator as shown in Fig. 4. It consists of stepped impedance lines, which are loaded by the bended open-end stubs. The feeding lines are matched to $50 \mathrm{ohm}$. The designed resonator has a $-3 \mathrm{~dB}$ cut-off frequency of about $3 \mathrm{GHz}$. The proposed resonator creates two transmission zeros at about $4.04 \mathrm{GHz}$ and $4.25 \mathrm{GHz}$ with corresponding attenuation levels of $-78.5 \mathrm{~dB}$ and $-79.3 \mathrm{~dB}$, respectively, as shown in Fig. 5.

The dimensions of the proposed resonator are optimized with an EM simulator (ADS). To obtain a more compact resonator; the stepped impedance lines are bent, as shown in Fig. 6.

The S-parameters of the proposed and modified resonator are shown in Fig. 7. As seen, there is no significant difference between the proposed and modified resonator. Also, the return loss of the modified resonator in the passband is improved from about $5 \mathrm{~dB}$ to $9 \mathrm{~dB}$, resulting in lower insertion loss in the passband. The coupling effects 


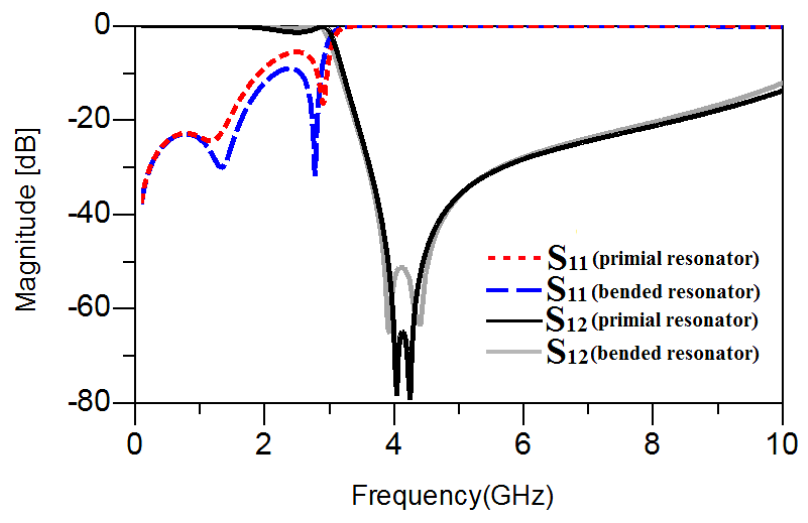

Fig. 7. The simulated S-parameters of the proposed and modified resonators.

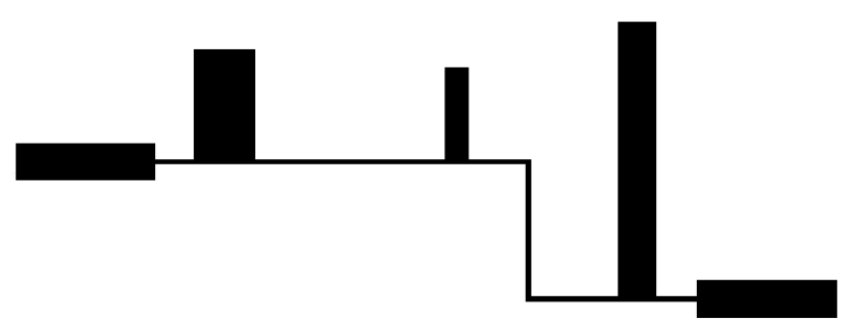

Fig. 8. The proposed suppressing cell.

between two resonators have been increased in the modified resonator. As applied in other references such as [13], the coupling between the stepped impedance microstrip lines can be used to make a better matching to have a lower insertion loss in the passband region.

The proposed modified resonator can provide a wide stopband from $3.4 \mathrm{GHz}$ to $8.2 \mathrm{GHZ}$, with two transmission zeros at $4.04 \mathrm{GHz}$ and $4.25 \mathrm{GHz}$, but the stopband width is not wide enough. Furthermore, the insertion loss in the passband has a value of $0.6 \mathrm{~dB}$, which is not good enough. To extend the stopband width, three discontinuities as steps in width are added to the high impedance feeding lines asymmetrically, as shown in Fig. 8, which operate as a suppressing cell. This results in the creation of transmission zeros at the undesired high frequencies, which suppresses the level of harmonics.

The simulated S12 parameter of the suppressing cell is illustrated in Fig. 9. The created transmission zeros at 9.5 GHz and $25.8 \mathrm{GHz}$, with the corresponding attention levels of $-48 \mathrm{~dB}$ and $-57 \mathrm{~dB}$, result in a wide rejection band, i.e. from $9 \mathrm{GHz}$ to $36 \mathrm{GHz}$. Therefore, the proposed LPF is the combination of the proposed modified resonator and the suppressing cell.

The layout of the proposed LPF is shown in Fig. 10. The filter is fabricated on a RT Duroid 5880 substrate with a dielectric constant $\varepsilon_{\mathrm{r}}$ equal to 2.2, thickness $h$ of $0.254 \mathrm{~mm}$ and loss tangent of 0.0009 . The dimensions of the LPF are: $W_{1}=W_{6}=0.8 \mathrm{~mm}, W_{2}=1.3 \mathrm{~mm}, W_{3}=1 \mathrm{~mm}$, $W_{4}=0.2 \mathrm{~mm}, W_{5}=0.5 \mathrm{~mm}, W_{7}=0.1 \mathrm{~mm}, W_{8}=3 \mathrm{~mm}, d_{1}=$ $3 \mathrm{~mm}, d_{2}=2.4 \mathrm{~mm}, d_{3}=d_{4}=2 \mathrm{~mm}, d_{5}=3 \mathrm{~mm}, d_{6}=6 \mathrm{~mm}$, $d_{7}=8 \mathrm{~mm}, d_{8}=3.7 \mathrm{~mm}$. The photograph of the fabricated LPF is shown in Fig. 11.

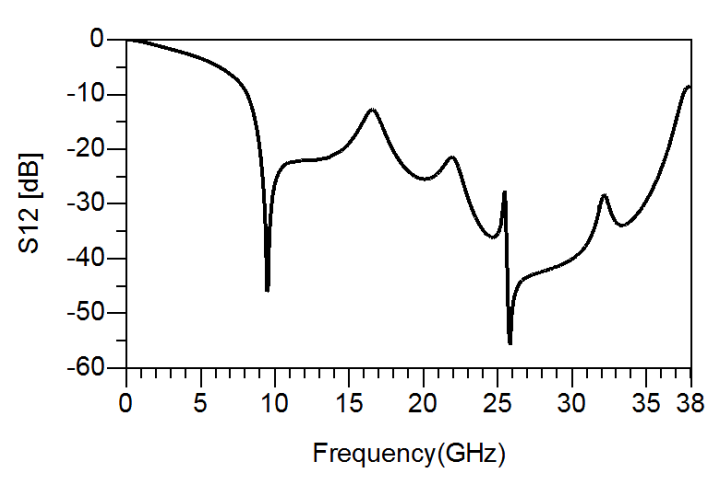

Fig. 9. The simulated S12 parameter of the proposed suppressing cell.

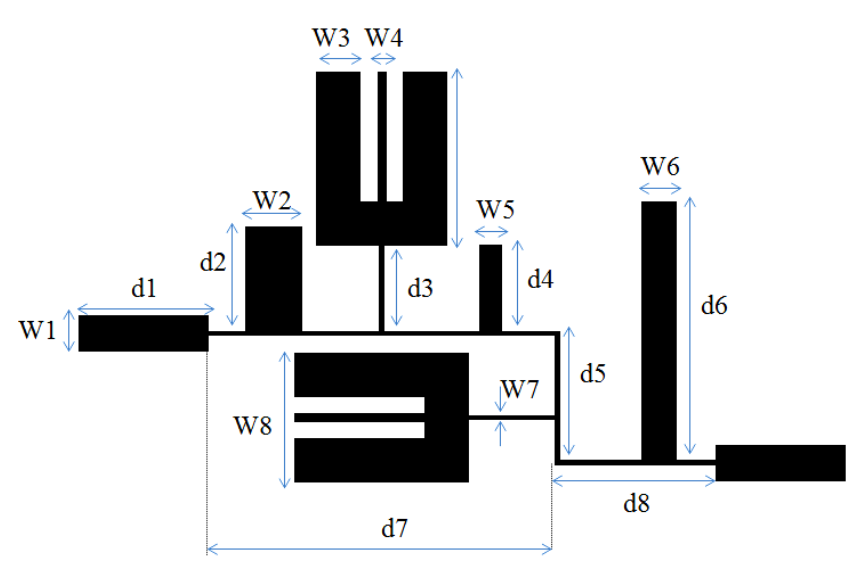

Fig. 10. The layout of the proposed lowpass filter.

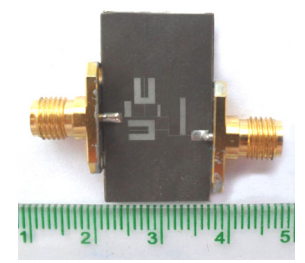

Fig. 11. The photograph of the fabricated lowpass filter.

\section{Simulation and Measurement}

The simulations and measurements are done using ADS software and the HP8757A network analyzer, respectively. The simulated and measured S-parameters of the fabricated filter are shown in Fig. 12. The difference between the simulated and measured result, which is more visible in higher frequencies, might be introduced by neglecting the losses of the dielectric and the conductor as well as the thickness of the metallic strip line [19].

It can be concluded that the $-3 \mathrm{~dB}$ cut-off frequency is located at $2.92 \mathrm{GHz}$ and an ultra wide stopband from $3.4 \mathrm{GHz}$ to $36.2 \mathrm{GHz}$ with the attenuation level of $-20 \mathrm{~dB}$ is obtained. The transition band is $0.48 \mathrm{GHz}$ from $-3 \mathrm{~dB}$ to $-20 \mathrm{~dB}$. The insertion loss is less than $0.12 \mathrm{~dB}$ in the passband, and the return loss is better than $16 \mathrm{~dB}$ in this region and nearby $0 \mathrm{~dB}$ through the stopband. Size of the filter is only $11.7 \mathrm{~mm} \times 9.6 \mathrm{~mm}$ without matching stubs. This size 
corresponds to compact electrical size of $0.156 \lambda_{\mathrm{g}} \times 0.128 \lambda_{\mathrm{g}}$, where $\lambda_{\mathrm{g}}$ is the guided wavelength at $2.92 \mathrm{GHz}$. The other parameter to show good performance of the proposed filter is group delay. Filter group delay is relating to the insertion loss of a filter. It is ideal to design a filter with flat group delay. As seen from Fig. 13, the maximum variation of the group delay in 80 percent of the passband region is only about $0.2 \mathrm{~ns}$. The performance of the proposed filter is compared with other works in Tab. 1. In this table, $f_{\mathrm{c}}$ is $-3 \mathrm{~dB}$ cut-off frequency; RL and IL are the return loss and insertion loss in the passband, respectively. The Suppression Factor (SF) is based on the stopband suppression. A higher suppression degree in the stopband leads to a greater SF. For instance, if the stopband bandwidth is calculated under $-20 \mathrm{~dB}$ restriction, then the $\mathrm{SF}$ is considered as 2 [17]. Also, SBW is the stopband bandwidth with considering $-20 \mathrm{~dB}$ rejection levels $(S F=2)$ for this work. The relative stopband bandwidth (RSB) for $-20 \mathrm{~dB}$ rejection level is given by [17]:

$$
\mathrm{RSB}=\frac{\text { stopband bandwidth }}{\text { stopband center frequency }}
$$

An important factor about lowpass filters is the ratio of stopband bandwidth to $-3 \mathrm{~dB}$ cut-off frequency $\left(\mathrm{SBW} / f_{\mathrm{c}}\right)$, which has a significant improvement from the other works in Tab. 1 .

According to Tab. 1, the proposed lowpass filter has the highest RSB (1.7) among the referred LPFs with suppression factor (SF) of 2 that emphasizes an ultra wide

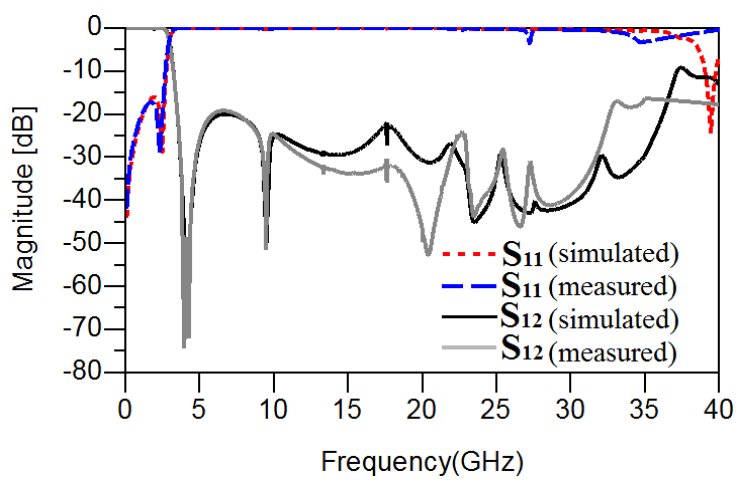

Fig. 12. The simulated and measured S-parameters of the fabricated LPF.

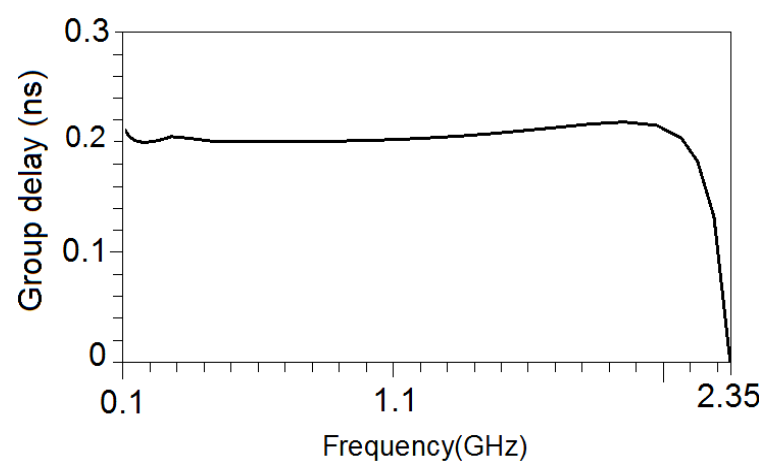

Fig. 13. Group delay through the passband.

\begin{tabular}{|c|c|c|c|c|c|c|c|}
\hline Ref. & $f_{\mathrm{c}}(\mathrm{GHz})$ & $S F$ & $R S B$ & $S B W / f_{\mathrm{c}}$ & $\begin{array}{c}R L \\
(\mathrm{~dB})\end{array}$ & $\begin{array}{c}I L \\
(\mathrm{~dB})\end{array}$ & $\begin{array}{c}\text { Size } \\
\left(\mathrm{mm}^{2}\right)\end{array}$ \\
\hline$[3]$ & 5.45 & 2 & 1.49 & 5.74 & 15 & 0.15 & 221 \\
\hline$[7]$ & 2.02 & 2 & 1.2 & 4 & 13.6 & 1 & 328 \\
\hline$[9]$ & 1.8 & 2 & 1 & 2 & 10 & 0.5 & 253 \\
\hline$[10]$ & 2.4 & 2 & 1.42 & 5 & 10 & 0.3 & 262 \\
\hline$[11]$ & 1.78 & 2 & 1.4 & 4.93 & 10.6 & 0.3 & 644 \\
\hline$[14]$ & 1 & 1.5 & 1.76 & 14.85 & 16.5 & 0.4 & 271 \\
\hline$[15]$ & 1.18 & 1.5 & 1.32 & 5.97 & - & - & 174 \\
\hline$[16]$ & 1.5 & 1.5 & 1.57 & 7.63 & - & - & 270 \\
\hline$[17]$ & 1.11 & 2 & 1.54 & 6.76 & 18.2 & 0.1 & 361 \\
\hline$[20]$ & 1.39 & 2 & 1.59 & 7.74 & 25 & 0.1 & 184 \\
\hline$[21]$ & 3.1 & 2 & 1.49 & 5.85 & 20.7 & 0.45 & 328 \\
\hline$[22]$ & 1.6 & 2 & 1.53 & 8.87 & 17 & 0.3 & 195 \\
\hline$[23]$ & 1.2 & 1.5 & 1.38 & 7.03 & 17 & - & 170 \\
\hline This work & $\mathbf{2 . 9 2}$ & $\mathbf{2}$ & $\mathbf{1 . 7}$ & $\mathbf{1 1 . 2 3}$ & $\mathbf{1 6}$ & $\mathbf{0 . 1 2}$ & $\mathbf{1 1 2}$ \\
\hline
\end{tabular}

Tab. 1. The performance comparison between the proposed LPF and other works.

stopband. The insertion loss in the passband (IL) is less than $0.12 \mathrm{~dB}$, and the size of the proposed filter is the smallest among the mentioned works, i.e. $112 \mathrm{~mm}^{2}$.

\section{Conclusion}

A compact asymmetric-shaped lowpass filter with an ultra wide stopband, using stepped impedance resonator, is presented. The simulated and measured results of the proposed filter are in good agreement. The proposed LPF benefits from low insertion loss, good return loss, ultra wide stopband and compact size. The overall size of the fabricated filter is $0.156 \lambda_{\mathrm{g}} \times 0.128 \lambda_{\mathrm{g}}$. The maximum variation of the measured group delay in the passband is only $0.2 \mathrm{~ns}$. With these characteristics, the proposed LPF could be employed for microwave communication applications.

\section{Acknowledgments}

The authors would like to thank Islamic Azad University, Kermanshah Brach, Kermanshah, Iran; for their financial supports.

\section{References}

[1] YANG, J., WU, W. Compact elliptic-function low-pass filter using defected ground structure. Microwave and Wireless Components Letters, 2008, vol. 18, no. 9, p. 578-580. DOI: 10.1109/LMWC.2008.2002447

[2] LI, L., LI, Z. F., MAO, J. F. Compact lowpass filters with sharp and expanded stopband using stepped impedance hairpin units. Microwave and Wireless Components Letters, 2010, vol. 20, no. 6, p. 310-312. DOI: 10.1109/LMWC.2010.2047457

[3] HAYATI, M., SHAMA, F. Compact microstrip low-pass filter with wide stopband using symmetrical U-shaped resonator. IEICE Electronics Express, 2012, vol. 9, no. 3, p. 127-132. DOI: 10.1587/elex.9.127

[4] REZAEI KHEZELI, M., HAYATI, M., LOTFI, A. Compact wide stopband lowpass filter using spiral loaded tapered compact micro- 
strip resonator cell. International Journal of Electronics, 2014, vol. 101, no. 3, p. 375-382. DOI: 10.1080/00207217.2013.780304

[5] ZHANG, C. F. Compact and wide stopband lowpass filter with novel comb CMRC. International Journal of Electronics, 2009, vol. 96, no. 7, p. 749-754. DOI: 10.1080/00207210902838610

[6] CAO, H., YING, W., LI, H., YANG, S. Compact lowpass filter with wide stopband using novel windmill resonator. Journal of Electromagnetic Waves and Applications, 2012, vol. 26, no. 17-18, p. 2234-2241. DOI: 10.1080/09205071.2012.732024

[7] HSIEH, L. H., CHANG, K. Compact elliptic-function low-pass filters using microstrip stepped-impedance hairpin resonators. Transactions on Microwave Theory and Techniques, 2003, vol. 51, no. 1, p. 193-199. DOI: 10.1109/TMTT.2002.806901

[8] TU, W. H., CHANG, K. Compact microstrip low-pass filter with sharp rejection. Microwave and Wireless Components Letters, 2005, vol. 15, no. 6, p. 404-406. DOI: 10.1109/LMWC.2005.850479

[9] HE, Q., LIU, C. A novel low-pass filter with an embedded bandstop structure for improved stop-band characteristics. Microwave and Wireless Components Letters, 2009, vol. 19, no. 10, p. 629 to 631. DOI: 10.1109/LMWC.2009.2029738

[10] LI, J. L., QU, S. W., XUE, Q. Compact microstrip lowpass filter with sharp roll-off and wide stop-band. Electronics Letters, 2009, vol. 45, no. 2, p.110-111. DOI: 10.1049/el:20093246

[11] HAYATI, M., LOTFI, A. Elliptic-function lowpass filter with sharp cutoff frequency using slit-loaded tapered compact microstrip resonator cell. Electronics Letters, 2010, vol. 46, no. 2, p. 143-144. DOI: 10.1049/el.2010.3136

[12] YANG, M., XU, J., ZHAO, Q., PENG, L., et al. Compact broadstopband lowpass filters using sirs-loaded circular hairpin resonators. Progress In Electromagnetics Research, 2010, vol. 102, p. 95-106. DOI: 10.2528/PIER09120901

[13] VELIDI, V. K., SANYAL, S. Sharp roll-off lowpass filter with wide stopband using stub-loaded coupled-line hairpin unit. Microwave and Wireless Components Letters, 2011, vol. 21, no. 6, p. 301-303. DOI: 10.1109/LMWC.2011.2132120

[14] WANG, J., CUI, H., ZHANG, G. Design of compact microstrip lowpass filter with ultra-wide stopband. Electronics Letters, 2012, vol. 48 , no. 14 , p. $854-856$. DOI: $10.1049 /$ el.2012.1362

[15] WANG, J., XU, L. J., ZHAO, S., GUO, Y. X., et al. Compact quasi-elliptic microstrip lowpass filter with wide stopband. Electronics Letters, 2010, vol. 46, no. 20, p. 1384-1385. DOI: 10.1049/el.2010.1569

[16] WAnG, J. P., GE, L., GUO, Y. X., WU, W. Miniaturised microstrip lowpass filter with broad stopband and sharp roll-off. Electronics Letters, 2010, vol. 46, no. 8, p. 573-575. DOI: 10.1049/el.2010.0329

[17] HAYATI, M., SHAMA, F., ABBASI, H. Compact microstrip lowpass filter with wide stopband and sharp roll-off using tapered resonator. International Journal of Electronics, 2013, vol. 100, no. 12, p. 1751-1759. DOI: 10.1080/00207217.2013.769180

[18] FOOKS, E. H., JAKAREVICIUS, R. A. Microwave Engineering using Microstrip Circuits. Prentice Hall of Australia, 1990. ISBN13: 978-0136916505

[19] DU, Z., GONG, K., FU, J. S., GAO, B., et al. Influence of a metallic enclosure on the S-parameters of microstrip photonic bandgap structures. IEEE Transactions on Electromagnetic
Compatibility, 2002, vol. 44, no. 2, p. 324-328. DOI: 10.1109/TEMC.2002.1003397

[20] HAYATI, M., MEMARI, H., ABBASI, H. Compact microstrip lowpass filter with wide stopband and sharp roll-off using triple radial stubs resonator. Applied Computational Electromagnetics Society Journal (ACES), 2013, vol. 28, no. 6, p. 513-520.

[21] HAYATI, M., VAZIRI, H. S. Wide stop-band microstrip lowpass filter with sharp roll-off using hairpin resonators. Applied Computational Electromagnetics Society Journal (ACES), 2013, vol. 28 , no. 10 , p. $968-975$.

[22] SHUAI, L., XU, J., XU, Z. Compact lowpass filter with wide stopband using stepped impedance hairpin units. Electronics Letters, 2014, vol. 51, no. 1, p. 67-69. DOI: 10.1049/el.2014.3673

[23] CHEN, X., ZHANG, L., PENG, Y., LENG, Y., et al. Compact lowpass filter with wide stopband bandwidth. Microwave and Optical Technology Letters, 2015, vol. 57, no. 2, p. 367-371. DOI: 10.1002/mop. 28853

\section{About the Authors ...}

Mohsen HAYATI received the BE in Electronics and Communication Engineering from Nagarjuna University, India, in 1985, and the $\mathrm{ME}$ and $\mathrm{PhD}$ in Electronics Engineering from Delhi University, Delhi, India, in 1987 and 1992, respectively. He joined the Electrical Engineering Dept., Razi University, Kermanshah, Iran, as an assistant professor in 1993. At present, he is a professor with the Electrical Engineering Dept., Kermanshah Branch, Islamic Azad University as well as Faculty of Engineering, Razi University, Kermanshah, Iran. He has published more than 185 papers in international and domestic journals and conferences. His current research interests include a microwave and millimeter wave devices and circuits, application of computational intelligence, artificial neural networks, fuzzy systems, neuro-fuzzy systems, electronic circuit synthesis, modeling and simulations.

Farzin SHAMA received the BE, the ME and $\mathrm{PhD}$ in Electronics Engineering from the Electrical Engineering Dept., Razi University, Kermanshah, Iran; in 2009, 2012 and 2016, respectively. At present, he is an assistant professor with the Electrical Engineering Dept., Kermanshah Branch, Islamic Azad University, Kermanshah, Iran. He has published more than 40 papers in international and domestic journals and conferences. His research interests include microwave engineering, active and passive analog circuits design and fabrication, and artificial neural networks. He was proud to achieve superior researcher in the Engineering Faculty of Razi University, in 2011 and 2012. He has been selected as top student of Iran, awarded by First Vice President of Iran in 2015. 